\title{
Pengembangan Sistem Informasi Program Kusta Berbasis Geografis di Kabupaten Cirebon Tahun 2005
}

\section{Haeria*}

\begin{abstract}
Abstrak
Kusta yang disebabkan oleh infeksi Mycobacterium leprae merupakan penyakit menular dengan masalah yang sangat kompleks. Tiga tahun terakhir, Kabupaten Cirebon yang melaporkan 1.207 penderita kusta (Prevalence 1,69/ 10.000 penduduk), belum mencapai tahap eliminas sehinga penularan masuh berlansung. Tujuan penelitian mengembangan sistem informasi kusta berbasis geografis yang dapat dijadikan solusi percepatan eliminasi kusta di Kabupaten Cirebon. Metoda yang digunakan adalah System Development Life Cycle, yaitu planning, analysis, design, implementation, maintenance dan evaluation system. Hai tersebut dilakukan dengan memadukan konsep Data Base Management System dan data spasial. Hasil analisis sistem dapat mengidentifikasi masalah manajemen penanggulangan kusta serta alternatif solusi pada level input, proses dan output. Data dan informasi dikumpulkan melalui wawancara, dan telaah dokumen. Sistem ini didesain untuk kemudahan input data dan otomasi proses pengolahan menjadi informasi. Interpretasi epidemiologis kusta pada visual peta dapat mengetahui model difusi transmisi kasus dan jangkauan pelayanan kesehatan (Puskesmas) dalam penanggulangan kusta.
\end{abstract}

Kata Kunci: Sistem informasi geografis, eliminasi, kusta

\begin{abstract}
Leprosy caused by Mycobacterium leprae is a contagious disease that generates complex problems. Over the last three years, the District of Cirebon reported 1207 leprosy cases (prevalence rate 1.69/10.000 population) and had not yet reach leprosy elimination situation, thus the disease was keep spreading. The purpose of this system development was to develop an application of Leprosy System Information Program Based on geographical information system for leprosy elimination acceleration program in Cirebon. The method used in this study was System Development Life Cycle method (planning, analysis, design, implementation, maintenance, and evaluation), by combining Data Base Management System concept and spatial data. Data and information needed were collected by interview and document observation. The system was designed for facilitating data input and automation of its process mechanism to produce information. Output were in form of regular report, tabulation, graphic, and area endemic mapping information with urban smallest observation unit. Epidemiologic interpretation on leprosy case from visual map can identify case transmission diffusion model and health service (Puskesmas) range capacity in leprosy elimination.
\end{abstract}

Keywords: Geographical information system, elimination, leprosy 
Upaya pengembangan kesehatan terfokus pada menurunnya angka kesakitan, kematian dan kecacatan yang disebabkan oleh penyakit menular dengan mencegah penyebaran dan mengurangi dampak sosial akibat penyakit sehingga tidak menjadi masalah kesehatan. ${ }^{1}$ Penyakit kusta merupakan salah satu penyakit menular yang menimbulkan masalah yang sangat kompleks, selain di bidang medis juga menjadi masalah sosial, ekonomi dan psikologis yang cukup serius, dan akhirnya menjadi masalah kesehatan masyarakat yang lebih luas. ${ }^{2}$

Tahun 1991 World Health Assembly (WHA) mengeluarkan resolusi program eliminasi, yaitu untuk menurunkan angka kesakitan kusta kurang dari 1 per 10.000 penduduk, sehingga penularan penyakit ini menjadi sangat rendah dan tidak akan menjadi masalah kesehatan masyarakat lagi, ${ }^{3}$ dan mencanangkan strategi global yang menitik beratkan pada penemuan kasus dan penyediaan multi drug therapy (MDT) dengan melaksanakan persiapan, kegiatan pokok, bantuan dan evaluasi sehingga menurunkan insidens dan prevalens sampai ke tingkat kabupaten dan akan tercapai eliminasi kusta.

Data yang didapat tahun 2002 di Indonesia telah mencapai eliminasi kusta dengan jumlah penderita sebanyak 19.805 kasus dengan angka prevalensi sebesar 0,95 per 10.000 penduduk, tetapi pada tingkat daerah masih ada 13 propinsi dan 111 kabupaten yang belum mencapai eliminasi. Sebagian besar $(70,16 \%)$ penderita kusta tercatat berada di Jawa Timur, Jawa Barat, Jawa Tengah, Sulawesi Selatan, DKI Jakarta dan Irian Jaya. ${ }^{4}$ Jawa Barat merupakan penyumbang kedua terbesar jumlah penderita kusta setelah Jawa Timur terhadap jumlah penderita kusta nasional. Pada tingkat kabupaten dari beberapa kota dan kabupaten yang ada di Jawa Barat daerah yang selalu tinggi penderita kusta pada setiap tahun adalah Kabupaten Cirebon.

Program pemberantasan penyakit kusta di Kabupaten Cirebon menggunakan pengobatan sistem Multi Drug Therapy (MDT) yang mulai dilaksanakan tahun 1983, secara bertahap sampai tahun 2003 penderita kusta yang ditemukan mendapat pengobatan MDT mencapai 100\%, namun demikian penderita yang belum ditemukan dan belum mendapatkan MDT diestimasikan masih banyak. Selama tiga tahun terakhir sampai tahun 2003 angka penemuan penderita baru dalam keadaan tetap sebesar 20 per 100.000 penduduk dengan jumlah penderita sebanyak 1207 penderita dan angka prevalens di atas 1 per 10.000 penduduk dengan angka prevalens pada akhir bulan Desember tahun 2003 sebesar 1,69 per 10.000 penduduk, tingkat angka kecacatan dan kasus kusta anak yang tinggi serta proporsi tipe kusta Multi Basiler yang selalu di atas 65\%. Dengan kondisi itu Kabupaten Cirebon belum mencapai eliminasi. ${ }^{5}$

Pengumpulan dan pengolahan data program di tingkat kabupaten tersebut menggunakan sistem sentinel surveilans pemberantasan penyakit kusta. Pelaksanaan sistem tersebut belum didukung dengan sistem data dasar yang terintegrasi, sementara proses pendataan dilakukan secara manual dan luaran yang diperoleh masih sebatas laporan rekapitulasi. Perangkat keras dan lunak sudah tersedia namun belum dimanfaatkan secara optimal untuk transformasi data menjadi informasi. Operasional sistem sering mengalami kesalahan, sehingga laporan kurang akurat, kurang cepat dan tidak relevan serta informasi endemisitas wilayah belum diketahui karena analisis yang dilakukan terbatas.

Permasalahan program eliminasi kusta di Kabupaten Cirebon yang kompleks ini memerlukan inovasi informasi dan sistem yang mendukungnya. Seperti yang tercantum dalam undang-undang kesehatan nomor 23 tahun 1992 tentang kesehatan pasal 69 menyebutkan bahwa perlunya pengembangan sistem informasi kesehatan yang mantap agar dapat menunjang sepenuhnya pelaksanaan manajemen dan upaya kesehatan dengan menggunakan teknologi dari yang sederhana sampai yang mutakhir di semua tingkat administrasi. ${ }^{6}$ Salah satu inovasi yang digunakan adalah kemajuan dibidang teknologi komputer dan software pendukungnya. Penggunaan komputer dalam sistem informasi kesehatan dilakukan berdasarkan beberapa pertimbangan antara lain efisiensi dalam proses dan analisis data besar secara cepat serta menghasilkan luaran laporan dan umpan balik bagi yang memerlukan.

Secara umum kualitas sistem informasi dipengaruhi oleh 4 faktor, yaitu kuantitas data, kualitas data, relevansi dan kesesuaian waktu. Selain faktor tersebut sistem informasi akan berjalan dengan baik bila ditunjang oleh komitmen pimpinan yang memanfaatkan informasi secara berkala. Pengambilan keputusan dan kebutuhan informasi, memerlukan piranti yang tepat antara lain aplikasi sistem informasi geografis (Arcview SIG). Alat tersebut merupakan piranti yang sangat essensial dalam menyimpan, memanipulasi dan menganalisis data. ${ }^{7}$ Analisis bidang kesehatan menggunakan SIG yang merupakan sistem informasi kesehatan yang semakin penting berkaitan dengan penyebaran dan kecenderungan geografis pelayanan kesehatan. Hasil tersebut berhubungan dengan penyebaran dan cakupan serta berperan sebagai alat bantu indentifikasi sasaran kegiatan pelayanan kesehatan berdasar wilayah kerja. ${ }^{8}$

Percepatan program eliminasi kusta di Kabupaten Cirebon sangat membutuhkan informasi yang tepat, cepat, akurat dan relevan. Untuk itu, perlu dilakukan analisis sistem informasi program eliminasi kusta dan kemungkinan pengembangan aplikasi komputer berupa perangkat lunak komputer yang diharapkan mampu mendeskripsi penyakit kusta guna menghasilkan informasi yang dibutuhkan dalam percepatan eliminasi penyakit kusta. Penemuan kasus kusta yang menetap pa- 
da angka 20 per 100.000 penduduk dan angka prevalens yang selalu lebih besar dari 1 per 10.000 penduduk dengan angka cacat dan kasus pada anak yang tinggi serta proporsi jenis kusta Multy Baciler yang selalu di atas $65 \%$ merupakan masalah kesehatan masyarakat yang terus berlanjut di Kabupaten Cirebon.

Hal itu tersebut mengindikasikan kegiatan penemuan kasus kusta secara aktif di lapangan yang rendah, informasi wilayah endemis kusta yang tidak diketahui, dan data perkiraan kasus kusta yang akurat pada tiap wilayah puskesmas belum tersedia. Keadaan ini mengakibatkan penularan kasus yang semakin meluas yang memperbanyak penderita kusta, menyebabkan penderita cacat, kasus kusta anak dan masalah kesehatan ataupun sosial ekonomi yang lebih serius. Keadaan tersebut terjadi karena keterbatasan pelayanan sebagai akibat sistem informasi program yang belum berjalan baik. Akibatnya, informasi yang diperlukan oleh pengambil kebijakan kurang akurat, tidak relevan dan kurang cepat sehingga program eliminasi kusta di Kabupaten Cirebon belum tercapai.

\section{Metode}

Pengembangan sistem dilakukan dengan menggunakan pendekatan terstruktur mengikuti tahapan siklus hidup pengembangan sistem. Tahapan tersebut meliputi perencanaan, analisis, perancangan dan pelaksanaan. Tahap pelaksanaan dibatasi sampai pada kegiatan dokumentasi sistem. Pada tahap perencanaan, dilakukan identifikasi peluang pengembangan sistem berdasarkan kelayakan ekonomi, teknis dan organisasi. Pada tahap analisis, dilakukan identifikasi penyebab masalah pada sistem yang telah ada, identifikasi kebutuhan informasi dan penetapan indikator yang diperlukan. Selain itu, dilakukan pengkajian output yang diharapkan, pengkajian instrumen yang digunakan dan pengkajian proses transformasi data. Pada tahap perancangan, dilakukan pembuatan model pengembangan sistem baru yang terdiri dari model fisik dan logik dengan menggunakan sistem bagan alir. Selanjutnya, dilakukan perancangan masukan, keluaran, basis data, teknologi dan pengendalian sistem. Pada tahap pelaksanaan, dilakukan pemrograman/ pengkodean, pengujian dan dokumentasi sistem. Metode yang digunakan untuk pengukuran kualitatif adalah wawancara untuk memperoleh data primer dengan menggunakan pedoman wawancara yang telah disiapkan dan observasi. Untuk memperoleh data sekunder, dilakukan pemeriksaan data (studi dokumentasi) terhadap laporan-laporan yang berkaitan dengan penelitian ini.

Informan diambil berdasarkan metode purposive (non probability) dan dipilih sesuai prinsip yang berlaku dalam metode penelitian kualitatif, yaitu kesesuaian dan kecukupan. Hal tersebut berarti pemilihan informan dilakukan berdasarkan pengetahuan yang dimiliki yang berkaitan dengan topik penelitian dan kecukupan. Dengan demikian, data yang diinginkan diperoleh secara lengkap dari informan. Pada penelitian ini, informan kunci adalah orang-orang yang memiliki hubungan langsung dengan program pemberantasan penyakit kusta. Mereka yang dilibatkan dalam wawancara mendalam adalah pegawai yang ada di tingkat Dinas Kesehatan Kabupaten. Hal tersebut sesuai dengan tujuan penempatan pengembangan sistem informasi yang akan digunakan meliputi Kepala Dinas Kesehatan, Kepala Bidang P3M; Kepala Seksi Pemberantasan Penyakit Menular; Pengelola program P2 Kusta di Dinas Kesehatan Kabupaten Cirebon.

Analisis data dilakukan dengan mendeskripsikan; kegiatan yang dilakukan oleh program (what), orang yang terlibat dalam program (who), lingkungan kerja (where), waktu pengelolaan data dan pengambilan keputusan (when), mekanisme atau prosedur yang ada (how) dan alur pelaporan kegiatan program eliminasi kusta.

Hasil

Pada tiga tahun terakhir, Kabupaten Cirebon belum mencapai eliminasi kusta seperti yang diharapkan. Prevalence rate yang berada di atas 1 per 10.000 penduduk tersebut merupakan indikator kusta yang masih besar. Hal tersebut masih perlu dicermati, mengingat semua kasus yang ada di masyarakat atau kasus backlog belum ditemukan (Lihat tabel 1).

Selama tiga tahun terakhir, masih banyak desa dengan sebaran penderita kusta yang bervariasi setiap tahun, meliputi endemisitas tinggi (34,0 - 37,7\%), endemik rendah (2) $(8,5-9,2 \%)$, dan endemik rendah (1), (53,1\%$57,5 \%)$. Desa yang tidak pernah ditemukan kasus kusta adalah $108(25,47 \%)$. Berdasarkan wilayah kerja puskesmas, endemik tinggi $(65,9-84,1 \%)$, endemisitas rendah (2) (13,6- 27,3\%) dan endemik rendah (1) antara $(2,3 \%-9,1 \%)$ (Lihat tabel 2).

Data dan informasi yang terkumpul hasil wawancara, observasi dan studi dokumen diketahui bahwa terdapat masalah-masalah dalam sistem informasi program eliminasi kusta di Dinas Kesehatan Kabupaten Cirebon. Permasalahan tersebut diuraikan menurut sistem alur informasi data menjadi informasi, yang dikelompokkan menjadi masalah input adalah pengumpulan data, masalah proses adalah pengolahan data dan penyajian data, masalah output adalah pemanfaatan data, masalah sumber daya tenaga dan sarana serta masalah mekanisme umpan balik.

\section{Masalah Asupan}

Sumber daya manusia untuk melaksanakan sistem informasi program eliminasi kusta di tingkat kabupaten masih sangat terbatas, berupa satu orang dengan latar belakang pendidikan SMA. Sarana dan prasarana pen- 
Tabel 1. Kasus Kusta di Kabupaten Cirebon, Tahun 2001 - 2003

\begin{tabular}{lccccc}
\hline Tahun & Kasus Baru & Total MDT & $\begin{array}{c}\text { Kasus Akhir } \\
\text { Tahun }\end{array}$ & $\begin{array}{c}\text { Case Detection Rate } \\
\mathbf{/ 1 0 0 . 0 0 0}\end{array}$ & $\begin{array}{c}\text { Prevalence Rate } \\
/ \mathbf{1 0 . 0 0 0}\end{array}$ \\
\hline 2001 & 398 & 770 & 335 & 20,67 & 1,74 \\
2002 & 402 & 739 & 305 & 20,56 & 1,56 \\
2003 & 407 & 712 & 311 & 20,59 & 1,57 \\
\hline
\end{tabular}

Tabel 2. Endemisitas Kusta di Wilayah Kerja Kabupaten Cirebon

Tahun 2001 - 2003

\begin{tabular}{lccccccc}
\hline \multirow{2}{*}{ Tahun } & \multicolumn{3}{c}{ Endemisitas Desa } & & \multicolumn{3}{c}{ Endemisitas Puskesmas } \\
\cline { 2 - 3 } & $\begin{array}{c}\text { Endemik } \\
\text { Tinggi }\end{array}$ & $\begin{array}{c}\text { Endemik } \\
\text { Rendah (2) }\end{array}$ & $\begin{array}{c}\text { Endemik } \\
\text { Rendah (1) }\end{array}$ & & $\begin{array}{c}\text { Endemik } \\
\text { Tinggi }\end{array}$ & $\begin{array}{c}\text { Endemik } \\
\text { Rendah (2) }\end{array}$ & $\begin{array}{c}\text { Endemik } \\
\text { Rendah (1) }\end{array}$ \\
\hline 2001 & 144 & 36 & 244 & & 37 & 6 & 1 \\
2002 & 160 & 39 & 225 & & 29 & 11 & 4 \\
2003 & 147 & 39 & 238 & & 31 & 12 & 1 \\
\hline
\end{tabular}

dukung berupa perangkat keras dan perangkat lunak komputer sudah tersedia dengan spesifikasi yang memadai, dan dilengkapi dengan "software" LBS program surveilance sentinel kusta. "Software" tersebut tidak digunakan karena disamping pengelola program tidak mampu mengoperasikannya juga karena "software" tersebut sulit untuk digunakan memasukan data dan kurang berfungsi dalam otomasi output informasi indikator program yang diharapkan. Dengan demikian, sarana dan pra sarana yang ada tampaknya sudah mendukung, tetapi perlu pengembangan software untuk mempermudah pengoperasian. Selain itu, perlu dilakukan peningkatan pemanfaatan teknologi, karena dengan spesifikasi yang ada komputer dapat digunakan untuk mengurangi beban pekerjaan.

Kelengkapan dan ketepatan waktu laporan merupakan indikator penting dalam kinerja petugas. Pengelola program di kabupaten sudah membuat absensi laporan masuk secara rutin, dalam pengumpulan data diperoleh rata-rata laporan yang masuk per bulan $77 \%$ (indikator yang diharapkan adalah 95\%). Namun, tidak dilakukan penilaian terhadap kelengkapan dan lampiran laporan yang berupa daftar data pengobatan penderita, lampiran laporan tersebut merupakan alat verifikasi laporan rekap LBS, oleh sebab itu akurasi data tampaknya belum optimal. Laporan yang terkumpul disimpan, tetapi penempatan laporan yang dikirimkan Puskesmas tidak tersusun baik dalam file tersendiri, sehingga terlihat berceceran yang kemungkinan dapat hilang dan kesulitan mencarinya ketika dibutuhkan.

\section{Masalah Proses}

Ketidaklengkapan dan keterlambatan pelaporan program eliminasi kusta dari puskesmas berpengaruh terhadap hasil analisis data. Hasil analisis menjadi tidak akurat, tidak relevan dengan kondisi yang sesungguhnya di lapangan. Hasil analisis data hanya disesuaikan dengan kebutuhan program tingkat propinsi dan pusat, belum dimanfaatkan untuk kebutuhan daerah sendiri dalam akselerasi eliminasi kusta. Proses pengolahan data masih dilakukan secara manual dengan memasukkan daftar data penderita ke dalam buku registrasi monitoring dan evaluasi pengobatan. Setelah itu, dilakukan rekapitulasi dengan menggunakan kalkulator untuk kemudian dimasukan ke media komputer dengan menggunakan program microsoft excel. Hal tersebut mengakibatkan informasi yang dihasilkan kurang akurat dan terlambat. Proses entry data dilakukan setiap tiga bulan sesuai dengan permintaan laporan oleh pihak propinsi, pusat dan subdit kusta. Dengan demikian, setiap akhir atau awal triwulan volume pekerjaan pengelola program terlihat menigkat.

Data yang telah dimasukan ke dalam komputer kemudian dicetak dan disimpan dalam bentuk dokumen kertas yang disatukan dengan dokumen-dokumen kegiatan yang lain. Kebutuhan data untuk program eliminasi kusta sulit dipenuhi, karena data tidak dapat disediakan secara cepat dan kesulitan mencari dan memilah dokumen. Selain itu, data perkembangan tiap bulan tidak tersedia karena entri data yang dilakukan tiap triwulan, sedangkan laporan puskesmas disampaikan tiap bulan. Masalah lain pada proses penyajian data adalah bahwa informasi kusta dilakukan hanya sebatas untuk memenuhi indikator program yang telah ditetapkan oleh program pemberantasan kusta, berupa laporan rekapitulasi kabupaten triwulanan sentinel kusta (LTS) dan laporan tahunan sentinel kusta (LTHS). Oleh sebab itu, informasi wilayah puskesmas yang merupakan daerah endemis maupun non endemis kusta sulit didapat.

\section{Masalah Luaran}

Luaran yang dihasilkan berupa laporan triwulanan dan tahunan yang menggambarkan jumlah penderita 
kusta di Kabupaten Cirebon. Kesulitan terjadi ketika ingin mendapatkan informasi indikator utama program dan besar masalah kusta di Kabupaten Cirebon. Akibatnya, pelaksanaan program penanggulangan kusta belum dilakukan berdasarkan evidance. Mekanisme umpan balik dari pengelola program yang berjalan selama ini belum optimal, karena hanya dilakukan ketika ada pertemuan puskesmas di kabupaten yang dilaksanakan setahun sekali jika ada dukungan anggaran. Arus informasi tersebut perlu diperbaiki, agar komunikasi program berjalan secara berkelanjutan dan informasi dapat dimanfaatkan secara cepat sesuai dengan kebutuhan.

Data dan informasi program penanggulangan kusta dibutuhkan sebagai acuan dalam pengambilan keputusan dan tindakan pada setiap kegiatan manajemen. Sistem informasi kusta tersebut akan bermanfaat jika dapat menampung kebutuhan pengguna informasi yang dapat diketahui melalui wawancara dan observasi. Dari studi ini dapat diindentifikasi kebutuhan informasi berikut:

1. Informasi penemuan kasus kusta yang memuat secara lengkap data dasar yang dapat digunakan untuk pemantauan dan evaluasi.

2. Informasi rekapitulasi kasus kusta dari data dasar penderita dapat digunakan untuk laporan pengobatan, laporan triwulanan, laporan tahunan.

3. Informasi jumlah kasus menurut kelompok umur anak dan jenis kelamin yang digunakan untuk mengetahui proporsi berdasarkan umur dan jenis kelamin penderita kusta.

4. Informasi hasil berdasarkan jenis pemeriksaan yang digunakan untuk memilih jenis intervensi yang efektif.

5. Informasi grafik untuk menggambarkan indikator utama kusta, yaitu prevalens rate, $\mathrm{CDR}$, tingkat kecacatan, tipe kusta, kasus anak, dan jenis kelamin serta tingkat kesembuhan penderita.

6. Informasi peta sebaran kasus kusta berdasar desa dan puskesmas serta teknik overlay, untuk mengetahui hubungan sebaran kasus kusta dengan tingkat kepadatan penduduk dan jangkauan pelayanan Puskesmas.

7. Informasi pemetaan endemisitas tingkat desa dan Puskesmas untuk keperluan pemantauan dan intervensi program yang efektif.

Pada tahap perancangan, telah dibuat diagram alir data, rancangan basis data, rancangan keluaran, rancangan masukan, rancangan transformasi data, rancangan teknologi dan rancangan pengendalian sistem berdasarkan standar yang ada. Tahap ini menghasilkan rancangan prototipe sistem yang siap untuk diuji di laboratorium. Pengujian dilakukan di laboratorium dengan menggunakan data program penanggulangan kusta di Kabupaten Cirebon, untuk kasus Bulan Januari sampai dengan Juni 2005. Selain itu, dilakukan pendokumentasian sistem dalam bentuk cetakan dan softcopy.

\section{Pembahasan}

Dalam pengembangan sistem informasi (system development) terdapat dua bagian yang harus diperhatikan, yaitu pemecahan masalah dan pemenuhan kebutuhan pengguna. ${ }^{9}$ Merujuk pada pernyataan tersebut, sistem informasi berbasis sistem informasi geografis ini yang digunakan untuk percepatan eliminasi kusta di Kabupaten Cirebon dikembangkan untuk mendukung dan membantu para pengambil keputusan dalam perencanaan untuk percepatan eliminasi kusta. Permasalahan sistem informasi yang ditemukan disajikan sebagai berikut:

\section{Level Input}

Dari analisis permasalahan didapatkan bahwa penyimpanan file yang belum terorganisasi menyulitkan pemenuhan kebutuhan data sistem program. Penggunaan formulir laporan LBS Puskesmas sering salah hitung. Peta desa belum tersedia. Penguasaan komputer atau piranti lunak oleh petugas sangat terbatas. Piranti linak pengolah data program penanggulangan kusta masih rumit dan belum berfungsi optimum.

Indikator merupakan berbagai variabel yang mengindikasi atau memberi petunjuk tentang suatu keadaan tertentu, sehingga dapat digunakan untuk mengukur perubahan. Suatu indikator seharusnya memenuhi persyaratan sederhana (simple), dapat diukur (measurable), bermanfaat (attributable), dapat dipercaya (reliable) dan tepat waktu (timely). Dalam suatu indikator ukurannya bersifat kuantitatif dan umumnya terdiri atas pembilang dan penyebut. 10

Dengan pengembangan sistem informasi tersebut, penyajian indikator yang dibutuhkan dapat dilihat secara cepat dan lebih lengkap. Hal tersebut dilakukan untuk pemantauan pencapaian program dan untuk kebutuhan laporan triwulan dan tahunan serta dapat mengetahui perubahan atau perkembangan kasus tiap bulannya. Indikator program yang disajikan secara optimal, akan mempermudah pemantauan dan pemilihan intervensi program yang sesuai dengan penanggulangan kasus kusta di Kabupaten Cirebon. Dengan demikian, percepatan eliminasi kusta diharapkan dapat tercapai lebih cepat.

Indikator utama program yang dihasilkan oleh sistem ini meliputi:

Angka prevalensi berguna untuk menyajikan besar masalah, menentukan beban kerja yang digunakan sebagai dasar perencanaan dan evaluasi. Angka ini menentukan stratifikasi endemisitas suatu wilayah, sehingga dapat diketahui wilayah yang sudah mencapai eliminasi atau masih dalam tingkat endemisitas tinggi. Angka prevalensi tersebut dapat disajikan dalam bentuk tabel, grafik dan peta dengan unit pengamatan terkecil adalah desa. Hal tersebut dilakukan untuk lebih mudah menganalisis besaran masalah yang terjadi pada skala wilayah yang paling kecil dan mengetahui model sebaran kasus 
dalam sistem informasi geografis dengan analisis spasial sebagai proses komunikasi untuk pengambilan keputusan.

Angka Penemuan Penderita (Case Detection Rate) berguna untuk mengestimasi angka insidens kusta yang ada di tingkat desa dan puskesmas. Angka ini juga berguna untuk menentukan stratifikasi endemisitas wilayah yang dikombinasikan dengan angka prevalensi. Angka penemuan penderita juga menggambarkan tingkat kinerja petugas puskesmas atau akses jangkauan pelayanan oleh puskesmas dalam penemuan kasus baru melalui pelaksanaan penemuan pasif dan aktif. Sajian informasi dilakukan dalam bentuk tabel dan grafik menurut wilayah puskesmas serta dalam peta dengan unit pengamatan terkecil desa. Hal tersebut akan memperkuat analisis sebaran kasus-kasus kusta baru pada skala wilayah yang paling kecil dan mengetahui model sebaran kasus dalam sistem informasi geografis dengan analisis spasial.

Proporsi MB dapat digunakan untuk memperkirakan sumber infeksi penyebaran dan menghitung kebutuhan obat. Proporsi MB di atas 65\% menunjukkan tingkat transmisi kasus kusta yang masih tinggi. Proporsi Cacat menunjukkan penampilan kerja atau kinerja dari petugas serta efektifitas program. Proporsi cacat tingkat II ditemukan di atas 5\% maka tingkat kinerja petugas puskesmas atau efektifitas program penanggulangan kusta perlu pembinaan lebih intensif lagi. Proporsi penderita anak berguna untuk mengestimasi insidens di antara penderita anak-anak dan memperkirakan sumber infeksi. Proporsi penderita anak di atas 5\% menunjukkan tingkat sumber infeksi masih tinggi terutama penderita tipe MB di antara penduduk setempat, keluarga atau tempat anak-anak tersebut bergaul dengan intens. Proporsi penderita perempuan berguna untuk mengestimasi insidens menurut jenis kelamin. Angka kesembuhan (RFT Rate) sangat penting dalam penilaian kualitas pengelolaan penderita selama pengobatan MDT, dengan RFT rate di atas 95\% hal ini menunjukkan kualitas pengelolaan penderita sudah baik.

\section{Kesimpulan}

1. Permasalahan sistem informasi eliminasi kusta di Dinas Kesehatan Kabupaten Cirebon ditemukan pada level input, proses dan output. Permasalahan pada sistem ini mengakibatkan perencanaan, pemantauan dan evaluasi serta intervensi program penanggulangan kusta tidak optimal dalam pelaksanaannya.

2. Sistem informasi berbasis sistem informasi geografis untuk eliminasi kusta (SIGEK) di Dinas Kesehatan Kabupaten Cirebon yang dikembangkan dengan menggunakan metode SDLC. Basis data dan output sistem yang didesain sesuai kebutuhan dapat menjadi alat bantu pengambilan keputusan untuk perencanaan, pemantauan dan evaluasi serta intervensi program yang tepat, cepat akurat dan relevan.

3. Keunggulan sistem yang dikembangkan meliputi kemudahan input data, didesain otomatisasi dalam perhitungan, kecepatan pengolahan data menjadi informasi dan akurasi data berdasarkan basis data yang digunakan. Informasi perkembangan kusta diberikan berdasarkan updating data yang dilakukan sesuai kebutuhan. Sistem informasi geografis yang terintegrasi dapat memberikan pemetaan strata endemisitas wilayah dan sebaran kusta dengan penyajian yang lebih jelas, akurat dan menarik. Selain itu, dapat memberikan informasi deskripsi difusi (pemencaran, penjalaran atau penyebaran) kusta di Kabupaten Cirebon.

4. Peluang implementasi sistem informasi geografis untuk eliminasi kusta (SIGEK) di Kabupaten Cirebon terlihat kondusif mendukung dengan tersedianya sarana dan sumber daya untuk pengembangan sistem serta dukungan dan komitmen pemerintah daerah dan pusat dalam penanggulangan penyakit kusta.

\section{Saran}

1. Mengingat sarana dan sumber daya pendukung sudah tersedia sehingga program penanggulangan kusta dapat dilaksanakan secara optimal. Agar SIGEK ini dapat di implementasikan dengan segera, diperlukan partisipasi pengguna dan manajemen, Untuk itu, sistem ini perlu sosialisasi pada pengguna dan tingkat manajemen serta diadakan pelatihan sebelum dioperasionalkan di lapangan.

2. Sebagai sumber data, hendaknya puskesmas mendapat umpan balik dan disupervisi secara berkala untuk meningkatkan kelengkapan dan ketepatan waktu laporan. Pengelola program kusta sebaiknya difungsikan untuk supervisi, sedangkan tenaga P3M yang ada dimanfaatkan untuk mengoperasikan komputer.

3. Untuk optimalisasi implementasi sistem perlu dilakukan evaluasi dan pemantauan untuk memperbaiki dan mengembangkan sistem berikutnya sesuai dengan siklus hidup sistem, sehingga menjadi lebih sempurna.

4. Aplikasi ini dapat dikembangkan lebih lanjut dalam desain prototipe sehingga dapat diperoleh penyajian yang lebih sempurna.

5. Aplikasi ini dapat dikembangkan pada tingkat puskesmas sehingga menjamin akurasi, efisiensi dan kecepatan processing data, dan lebih efektif dengan menggunakan sistem upload data dari puskesmas atau menggunakan online jaringan telepon atau jaringan internet ke Dinas Kesehatan.

6. Untuk efektif dan efisiensi dana dan tenaga program percepatan eliminasi kusta, intervensi program sebaiknya disesuaikan dengan tingkat endemisitas 
wilayah desa dan Puskesmas. Prioritas intervensi adalah desa atau Puskesmas dengan potensi penularan kusta yang tinggi, dengan tetap memantau daerah yang rendah.

7. Aplikasi SIGEK ini dapat dijadikan model pengembangan sistem informasi untuk penanggulangan kusta di Kabupaten lain.

\section{Daftar Pustaka}

1. Departemen Kesehatan RI. Rencana pembangunan kesehatan menuju indonesia Sehat 2010. Jakarta:Depkes RI; 1999.

2. Fakultas Kedokteran Universitas Indonesia. Kusta. Jakarta: Fakultas Kedokteran-Universitas Indonesia; 2003.

3. World Health Organizatiton. Pengembangan indikator untuk memantau kemajuan menuju kesehatan bagi semua di tahun 2010.1990.
4. Departemen Kesehatan RI. Buku pedoman pemberantasan penyakit kusta. Jakarta: Ditjen PPM \& PL; 2000.

5. Dinas Kesehatan Kab. Cirebon. Profil kesehatan kab. cirebon tahun 2003.Cirebon: 2003.

6. Departemen Kesesehatan RI. Sistem informasi geografis (SIG): modul pelatihan manajemen P2M \& PL terpadu berbasis wilayah kabupaten/kota. Jakarta: Depkes RI Ditjen P2M\&PL; 1992.

7. Prahasta, E. Konsep-konsep dasar sistem informasi geografis. Bandung: Informatika; 2002.

8. Hartono, B. Pengembangan SIK daerah : materi fasilitasi. Jakarta: Pusdatin Depkes RI; 2002.

9. Jogiyanto H. Analisis dan desain sistem informasi. Yogyakarta: Andi Offset; 2001.

10. Green, Lawrence W. Health promotion planning: an educational \& evironmental approach. 1992; 2nd edition. xxi. 506p. 